In the middle part of this century health services research was part of the radical movement. It was concerned with affecting the climate of policy formation and in defining future options. ${ }^{1}$ Increasingly in Britain it has become a tool of management. This editorial looks at this trend in a number of the fields covered by health services research. It then discusses the reason for the trend and its implications.

\section{Studies of patients}

One part of the radical movement was to consider the views and experiences of patients and to take into account the effects on them of different forms of treatment and of different types of care. This was basically successful. It is now much more widely recognised that patients' experiences and views should be an integral part of drug trials and of exercises assessing ways of delivering care. Studies of screening now usually take into account the anxieties that can be caused and review the effects on patients of delays and false positive results.

However, alongside these welcome trends has gone an increasing emphasis on patient satisfaction studies which are being used for management purposes. Surveys of patients can yield information about the functioning of services, and about patients' knowledge and preferences, and whether they feel they have choices about their care and treatment. Many current management studies concentrate exclusively on patient satisfaction over limited and mundane matters and ignore these more useful fields. Satisfaction studies yield results which are difficult to interpret and are likely to encourage complacency. They can discourage innovation and change since patients tend to be satisfied with the services they have experienced and wary of those they have not. Focusing on satisfaction can also mean that important failures of a service go unrecognised while more superficial ones are highlighted.

\section{Measurement of general or specific needs}

It is difficult to be certain that health services research is concentrating more on specific needs and specific services than on more general measures of need, but it appears that this is so. The earlier concentration on differences between social classes in mortality, morbidity, and the distribution of services identified inequalities but has been unsuccessful in reducing them; many differences have widened. The more specific approach is more likely to have clear cut and practical implications. Needs, or requirements, for particular services such as hip replacements, chiropody, cataract operations, and incontinence services can be assessed, and they give definite indications about the adequacy or lack of care provision. More general studies of health care needs give a less direct message and one which is more easily ignored. The more specific and more management orientated studies can have a more radical outcome.

\section{Cost-benefit analysis and QALYs}

Another change to more management orientated studies, the greater use of cost-benefit analysis, also deserves a cautious welcome. Cost should be one factor that is taken into account when choosing between different treatments or procedures-if it can be done in a cost-effective way; costing itself costs money and resources and its usefulness needs to be evaluated. The measurement of quality of life years (QALYs) is another potentially useful way of assisting decisions about which treatments are of most benefit to patients with a particular disease. However, the use of QALYs, or any other costeffectiveness approach, to decide which patients to treat is questionable. As Smith has pointed out, allocation of resources on a cost-effectiveness basis would run counter to the radical objective of reducing health variance and would tend to increase it. $^{2}$

\section{Evaluation}

The evaluation of both new and established treatments and procedures by randomised controlled trials is to be applauded. The approach of accumulating data from different studies has been usefully applied in the field of obstetrics by the National Perinatal Epidemiology Unit and it is good news that this procedure is now to be extended to other fields.

A less welcome trend has been a tendency to assume that new services, or changes in services, should be validated from their onset. Services take time to become established. They are often modified in the early stages of their development. An additional problem is that services are frequently initiated or changed by enthusiastic innovators who then move on, leaving them to decay or revert to their earlier forms. Some new measures are soon seen as misconceived and then rejected. In all these circumstances validation at an early stage is inappropriate or misleading as well as a waste of resources.

Another fashion is for the overelaborate trial with different stages of exploration, intervention, and evaluation. This process can take so long that the intervention has been superseded by the time it has been evaluated.

\section{Reason for trends}

The underlying cause for most of these trends has been the way health service research has been funded. In England the Department of Health, previously the Department of Health and Social Security, has been the main source of funds since the 1970s and these have been applied according to the Rothschild principle-the customer says what he wants, the contractor does it (if he can), and the customer pays. ${ }^{3}$

Inevitably then, health services research has been directed at problems identified by policy makers. To work effectively this principle is dependent on the ability of customers to identify researchable questions, or, failing that, on the willingness and 
skill of researchers to tease out the researchable issues from the questions posed by the customers. This type of successful collaboration has happened in the obstetric field.

However, in times of recession the Rothschild principle works particularly badly; researchers/contractors become less willing to say they cannot do what the customer wants, and more likely to present potential projects as if they will answer the customers' unanswerable questions. There is a temptation to make unrealistic or exaggerated claims for the value of research and to present results and proposals in a pretentious way. This is one reason for the inappropriate or premature evaluation of new services and for the overelaborate and lengthy assessments of intervention.

Recessions affect the funders too. As Moss, in his history of the Government Social Survey, points out, when "governments set out to limit social expansion, part of this process is an attempt to limit social investigation." 4 If there are to be cutbacks in services these are unlikely to be based on research; expansions stand a better chance of having such an input.

\section{Implications}

If and when a satisfactory collaboration between customers and researchers is achieved, practical and useful issues can be explored. In that situation there may be a good chance of the results being noticed and applied. And the results may have radical implications.

But the danger is that a management orientation can lead to research concentrating on issues of political significance and ignoring ones that are more important in relation to health care. The concerns of social reformers can also divert research resources to unproductive fields. In an article on health needs and the myth of infinite demand Frankel ${ }^{5}$ argues that "research activity has been concerned almost exclusively with the probability of neediness, in the tradition of the social reformers, not with the distribution of those who might be expected to benefit from particular interventions." He concludes "the task of satisfying demand is widely held to be fundamentally futile. The assumptions that underlie this pessimism should be questioned, and abandoned in favour of empirical determination of health-care requirements, with the assumption that there may be no need to ration those interventions of undoubted efficacy."

One reason why research has not contributed more effectively to this debate is that government departments are reluctant to sponsor research that might yield evidence which would be inconsistent with, or might undermine, current policy. This is a major disadvantage of the Rothschild principle, and has inhibited research into the effects of recent and planned changes in the organisation of the health service. If health services research is to be in a position to criticise policies and their implementation, other sources of funds are needed. At present the amount invested in such work is minute compared to the cost and complexity of the services. Yet "a well-structured health services research programme is essential to future health care policy and to adequate monitoring of a massive national investment."1

ANN CARTWRIGHT

1 Mechanic D. Prospect and problems in health services research. Milbank Memorial Fund $Q$ 1978; 56: 127-39.

2 Smith A. Qualms about QUALYs. Lancet 1987; i: 1134-6.

3 A framework for government research and development. Cmnd 4814. London: HMSO, 1971.

4 Moss L. The Government social survey: a history. London: HMSO, 1991: 260.

5 Frankel S. Health needs, health-care requirements, and the myth of infinite demand. Lancet 1991; 337: 1588-90. 